\title{
Connecting Industry: Building and Sustaining a Practice-based Research Community
}

\author{
Susan P. Williams \\ University of Koblenz-Landau \\ Institute for Information Systems Research \\ Faculty of Computer Science \\ Germany \\ williams@uni-koblenz.de
}

\author{
Petra Schubert \\ University of Koblenz-Landau \\ Institute for Information Systems Research \\ Faculty of Computer Science \\ Germany \\ schubert@uni-koblenz.de
}

\begin{abstract}
In this paper, we give a narrative account of the building and sustaining of a multi-organization practice-based research community (IndustryConnect). We begin with an examination of the motivations and theoretical foundations for the initiative, which brings together researchers and practitioners to investigate the design of the digital workplace and the use of enterprise collaboration systems. We discuss the arrangements, structures and research methods used and the challenges and rewards of practice-based research. These include: aligning stakeholder interests, serving both theoretical and practical outcomes and the role of research training and mentoring in the process of community building.
\end{abstract}

\section{Introduction}

There is growing discussion in the information systems (IS) literature and related research fields about the nature, form and purpose of scholarly research. Existing on multiple levels this discussion addresses: the subject matter of IS research and its scope and relevance [1]-[6]; the methods and methodologies in use [2], [7], [8]; and the locus of knowledge construction and the authority of professional knowledge [8]-[10]. It has also made visible the limitations of the variablescentered IS research paradigm and its capability to address these issues, as it "appears to distance researchers from organizational actors, such as managers, to whom they would give advice and counsel" [11, p. 474] and reduces problem domains to constructs, variables and correlations [12]. It is these drivers and limitations that have triggered renewed calls for more practice-based research, especially to examine emerging IS issues and provide a means for both "theorizing practice and practicing theory" [13]. The research landscape is changing from one that frames the gap between theory and practice as a problem of knowledge transfer (seeing theory and practice as two distinct forms of knowledge) to a knowledge production problem with researchers and practitioners involved in the co-production of knowledge [11], [13][15]. The challenge for researchers engaging in this practice-based research is to find research approaches for examining emerging and changing themes of practice and to draw on both scholarly and professional knowledge to create robust theorizations. In this paper we address these challenges through a reflexive account of the building and sustaining of a successful collaborative practice-based research community (IndustryConnect) and of the methods used to undertake practice-based research. Our aim is to present a 'model' for organizing such a community and to discuss the requirements and arrangements, rewards and challenges. The paper is organized as follows: we begin with an overview of our field of research and the theoretical foundations of our practice-based research initiative. This is followed by an in-depth discussion of the arrangements, structures and methods used to meet the interests of both university and industry partners and to ensure the long-term sustainability of the research community. We conclude with an analysis of the challenges and rewards of the IndustryConnect initiative and the implications for future practice-based research.

\section{Field of research and theoretical foun- dations}

In this section, we present the theoretical and personal motivations that underpin our research designs and drive our commitment to practice-based research. To provide context we begin with an overview of our field of research and explain how this motivates the need for a practice-based research approach. Our research program draws on theories from $\mathrm{CSCW}$, organizations and information systems and is focused on the 
digital workplace and the socio-technical change associated with the implementation and use of enterprise collaboration systems (ECS). ECS (e.g. IBM Connections) are large-scale, integrated software platforms that combine traditional groupware capabilities (e.g. shared workspaces, synchronous and asynchronous messaging, group calendars, document libraries) with social software components (e.g. wikis, blogs, social profiles, activity streams). Such systems have huge potential to transform the ways individuals, groups and organizations arrange, manage and conduct their work through, for example, improved team collaboration, better knowledge sharing, workflow and project coordination etc. [16], [17]. Representing a new form of information infrastructure these "socially-enabled" collaboration systems have a number of characteristics that make them especially interesting as a field of research and, as we discuss below, a subject for practicebased research.

ECS represent large-scale, geographically distributed installations, typically extending across multiple organizational departments and divisions and supporting large numbers of registered users. This requires us to go beyond studying single-site implementations, which only provide partial understanding, to examining the biography of such workplace technology [18] at different levels of analysis, in different locations and over multiple periods of time [18]-[20]. As Monteiro and Rolland [21] note, the study of such trans-situated use of technology requires us to extend contemporary practice-based research, which is largely local and situated, to also account for similarities in technologically mediated work practices across multiple contexts and timeframes. This requires a temporal view and ongoing access to ECS using organizations to be embedded into our practice-based research designs.

Another distinguishing characteristic of ECS is that they are largely designed in/through use [22], [23]. In contrast to systems such as ERP and CRM systems where use is usually mandatory, the use of the ECS is often voluntary [24]. The system is installed, made available for use and left open to the users to find suitable use-cases to meet their needs. ECS are therefore more malleable and open to interpretive flexibility [25] guided by processes of trial and error and evolutionary use discovery. This raises interesting research questions about: which use-cases emerge and survive; the technologies from within the ECS platform that are used to support these use-cases; the strategies that are used to embed them into everyday work practices and the benefits that arise. To date, scholarly research on the topic of socially enabled ECS has largely focused on their early adoption (e.g. [26]-[28]; less attention has been directed towards understanding the longerterm impact on work practices and organizations. This calls for research designs that are sensitive to the situated, contextual nature of socio-technical change [19], [20], [25], [29] and look beyond initial adoption; following projects into the phases of post-implementation change [21], [30], [31] and requiring the participation of the key actors involved. A limitation of the current body of ECS research is that it contains few in-depth, longitudinal empirical cases enabling us to understand and theorize about the degrees of similarities (and differences) in use across contexts and how they are being achieved [21].

Whilst there is much written about the need for practice-based research there is little guidance as to how this might be organized, especially around the methods for conducting collaborative research with multiple organizations and for producing empirically based theoretical and actionable knowledge. It is to this topic that we now turn.

\section{IndustryConnect: An Industry-based Research Community}

In the following sections we provide an overview and discussion of the arrangements, structures and methods used to meet the interests of both university and industry partners and to ensure the long-term sustainability of a practice-based research community. We begin with the background to IndustryConnect, its idea, objectives, participants and the ways that the work is organized. This is followed by a discussion of the research methods we have developed and adopted for this kind of practice-based research.

\subsection{Background, Idea, Mission, Objectives, Organization of Joint Work}

IndustryConnect began in 2010 as an initiative of the University Competence Center for Collaboration Technologies (UCT). It is a collaboration project between two research groups at a German University and a group of practitioners from companies, who all use the same, integrated Enterprise Collaboration System (ECS). The aims of this practice-based research community are i) to conduct research into problems and issues surrounding the implementation and adoption of ECS, i.e. activities of communication, coordination and active information exchange among employees ii) to exchange knowledge and experiences between the members and iii) to develop new insights and understandings about the complex socio-technical change surrounding ECS and the evolving digital workplace. 
The founders of IndustryConnect are two professors from the Computer Science Department at the University of Koblenz-Landau whose own research practice is strongly influenced by the British/Scandinavian schools of socio-technical systems and participatory design [32], [33] and the pragmatics of the German field of Wirtschaftsinformatik [34], [35]. Both are committed to an evidence-based research approach and to translating that evidence into theoretical and actionable outcomes. After several years of conducting practice-based research studies with individual companies they wanted to bring companies together to form a multi-organization research community. In addition to the aims for the community outlined above their belief is that practice-based research is itself an academic professional practice that must be nurtured and developed. Thus, bringing $\mathrm{PhD}$ students together with a community of practitioners will help these early career researchers to not only ensure that their research is relevant and reflects current practice in the field, but also help them to develop skills in the methods for developing and conducting industry-based research.

The practitioners are all collaboration experts; each is a key actor with responsibility for the introduction and use of the collaboration software within her/his organization. They represent a range of professional backgrounds including: information technology, business-related departments including: information/ knowledge management, internal communications, organizational processes and business development. The participating practitioners are committed to the exchange of information and experiences with their peers from other companies and to coordinated, collaborative research activity. They have a major interest in hearing stories from the field about "things that have worked for others", i.e. strategies, methods, tools and processes for adoption and successful organizational use of collaboration software. The university researchers are interested in gaining insights into the lived experiences of current practice, collecting empirical data with the companies, analyzing this data to make sense of this emerging topic and laying the foundations for theorization. The spirit of the group is of both a reflexive and reflective research community [36], [37].

Membership of the community is purposefully managed in two ways. Firstly, industry members are software user companies (that is end users of the ECS software); software vendors and IT consultants are explicitly excluded. Community participants have frequently commented on how important this situation is, and how they value the opportunity to discuss and address issues without the distraction of IT vendors and consultants trying to sell their services to the user companies. Secondly, admission to research community is "on invitation only" and by agreement with the existing participants. This arrangement makes sure that the participants have a joint interest and that the motivation is "problem solving and knowledge exchange" and not "making business" (i.e. finding customers). The member base has been constantly growing since the launch of the project, as of August 2016 the IndustryConnect community consists of 49 individuals (37 practitioners, $6 \mathrm{PhD}$ students, 2 University professors and 4 student assistants) representing 21 organizations. The companies represent a range of industries, including footwear retailing, electronic components, sound systems, aviation, vehicle inspections, chemical/construction products, construction services, automotive components, public administration services and others. On joining the community, each new member pays a fee to participate in an introductory workshop that introduces them to practice-based research methods and the theoretical foundations of the current work. Further funding is sourced on a project-by-project basis through bilateral research projects with individual companies. Each industry partner takes a turn in hosting the face-to-face meetings and covers the cost of hosting the meeting at their company's premises.

IndustryConnect is a research program rather than a research project that combines a series of distinct yet integrated projects into one joint initiative. It is organized around a process of participatory action research [38] led by the university research team working with industry professionals as part of a "community of practice" with the goal of progressive investigation of ECS and the digital workplace. The research activity has a clear structure and the participating researchers use a set of joint research methods and instruments to share insights and combine findings from multiple individual studies. In the next sections, we describe the yearly cycle and arrangements of work and the research methods used.

\subsection{Timing: Activities Over the Year}

The work in IndustryConnect is organized into a series of events and activities in a yearly research cycle (cf. Figure 3). The three pillars of work are the 1) virtual workspace (an online community); the 2) collaborative workshops (physical meetings) and the 3 ) bilateral research work (one-on-one research with individual practitioners/ companies).

The virtual workspace is the persistent home of the IndustryConnect community. It is hosted on a collaboration platform (the same collaboration software that is in the focus of the project) and actively managed by the university research team. One of the researchers acts as the community manager, which involves wel- 
coming new members to the community and managing communication about the arrangements for the twiceyearly face-to-face meetings. Each community member has a "social profile" (a common feature of this type of social software) that contains background information (e.g. contact information, affiliation, location) and interests. Members can connect to each other (using the "invite to my network" feature) and recommend content to their followers. The virtual workspace is a closed (private) community and all information there is only available to community members. The virtual workspace is used to plan and prepare the physical meetings (e.g. by using the "event feature" of the software and the wiki for the planning of the agenda). It also serves as the "community knowledge base". All documentation from the workshops as well as all other available research findings are stored in the wiki and files component of the workspace. Between the physical meetings, conversations on selected topics or questions continue in the forum. Additionally, each $\mathrm{PhD}$ student manages a forum dedicated to their individual $\mathrm{PhD}$ topics where they present the progress of their work and actively invite comments from the practitioners.

The twice-yearly physical workshops are the engine that drives activity in the community. The meetings are aimed at bringing the participants together; this is where they get to know each other and build trust and relationships. The workshops usually begin with a social event in the afternoon of the arrival day (e.g. a visit to the local Christmas market, winery, museum etc.) and are followed by a joint dinner where networking takes place and ideas and problems are discussed in a more casual atmosphere. The actual meeting takes place the next day and comprises a full agenda of presentations, impulse speeches, focus groups, metaplanning work, open discussions, agenda setting and the identification of research work to be conducted between meetings. The university research team coordinates the data collection and data analysis of this follow up work. The preliminary findings are presented in the virtual workspace and the detailed findings are presented at the next face-to-face meeting. The participating organizations take turns in hosting and organizing the physical workshops at their premises; meetings have now been held in locations all over Germany. This means that participating companies have an active role in the community management and gives participants the opportunity to experience the work environments of their community partners.

The bilateral work is the backbone of the program. In the periods between physical meetings, the university researchers and $\mathrm{PhD}$ students work one-on-one with the participating companies in order to conduct indepth studies and collect data for their thesis projects. They visit selected participants on site and for example, conduct interviews, organize workshops with employees, run surveys and use other forms of data collection instruments (see method section below). The bilateral work is geared at special topics of mutual interest between the researchers and the company. Where they are of general interest for the whole community (and this is usually the case) the interim findings are presented to everyone at the next physical meeting.

\subsection{Conducting collaborative industry-based research}

Collective knowledge base. A unique feature of this practice-based research is that all work (including discussions, presentations, focus groups) that happens during the physical meetings is documented in detail by the university research team and shared with the whole community. The participating researchers continue their work on the topics between the physical meetings and make the results available in the form of documents, tables, infographics, descriptions of methods, techniques or guidelines. This way the community is building a collective knowledge base.

Some topic sections are frequently revisited and their content is growing continuously. For example, every time a new industry partner joins the community and attends their first meeting, they introduce themselves and their background in a 
structured form. Their input is then added to a permanent section called drivers, barriers, motivation and painpoints. "Drivers and barriers" reflects the view of their organization; it presents the reasons why the organization is engaged in the collaboration project and has decided to implement the ECS and the problems they faced in the process. "Motivation and painpoints", on the other hand, describes the personal point of view of the participating individual, their personal motivation to promote collaboration in the company and their current challenges in the implementation project. Every new participant goes through this exercise and the documentation in the Wiki is updated after every event. This has led to a collection of data about ECS drivers/barriers and motivation/painpoints from the 20 member companies. Since this data is recorded at an early point stage of the company's collaboration initiative, it serves as an ideal anchor measure [39] for later comparisons in the study of socio-technical change as we observe how initiatives change over time. Other permanent collections of data are "collaboration scenarios" and "strategies for the implementation of the $E C S$ ", which provide input to the research work. A section on "tips and tricks in the ECS" is a place where new learning about the ECS can be shared and it is through these discussions of problems and workarounds that many of the unintended consequences of ECS implementation and adoption are first made visible.

Interaction at the workshops. The workshops are composed of different activities designed to suit the stage of the research and the research needs of the participants. Activities adopt different approaches; comprising, for example, presentations by practitioners and academics about research findings, interactive elements (moderated discussion and meta plan technique), focus groups and open conversation on selected topics. Some activities are contained in every workshop, e.g. the introduction of new members (drivers, barriers, motivation und painpoints, as described above), im- pulse speeches by the practitioners, follow-up of milestories and presentation of ongoing research. The largest activity block is dedicated to a focus topic with interactive elements (usually organized with meta plan techniques) using standard methods and instruments for moderated data collection e.g. Delphi method, postits/note cards to identify issues or factors, voting on importance or impact, etc. Focus topics of recent meetings have been "Long-term management of Social Business Documents", "Identification of Collaboration Scenarios" and "Social Analytics Requirements and Methods". In the next section, we will introduce two methods that we explicitly developed for our practicebased research and which we use in our bilateral, longitudinal work with the companies.

Methods: eXperience Case Studies and Milestories. We use two specific methods, eXperience cases and milestories, to capture in depth information about each organization and its collaboration projects, and the ways these evolve and are shaped both spatially and temporally.

Experience cases. The eXperience Method is a methodology for writing research cases of IT implementations [40]. The eXperience template for writing cases provides authors with suggested sections containing guiding questions for the writing of a case. At its core, eXperience cases are structured into parts describing the background of the company, the reasons for the implementation of a technology, the four eXperience views (business, process, application, technical), the actual implementation project, the experiences of the participants since go-live and a final assessment of the key lessons learned from this project. The method also provides standardized graphical modeling approaches for the four views, which have proven to be useful for authors (they can discuss the content of the interview with their interview partner using these graphics) and they facilitate comparison between different cases. At its heart, the eXperience method is a method for data collection, which means that supple-

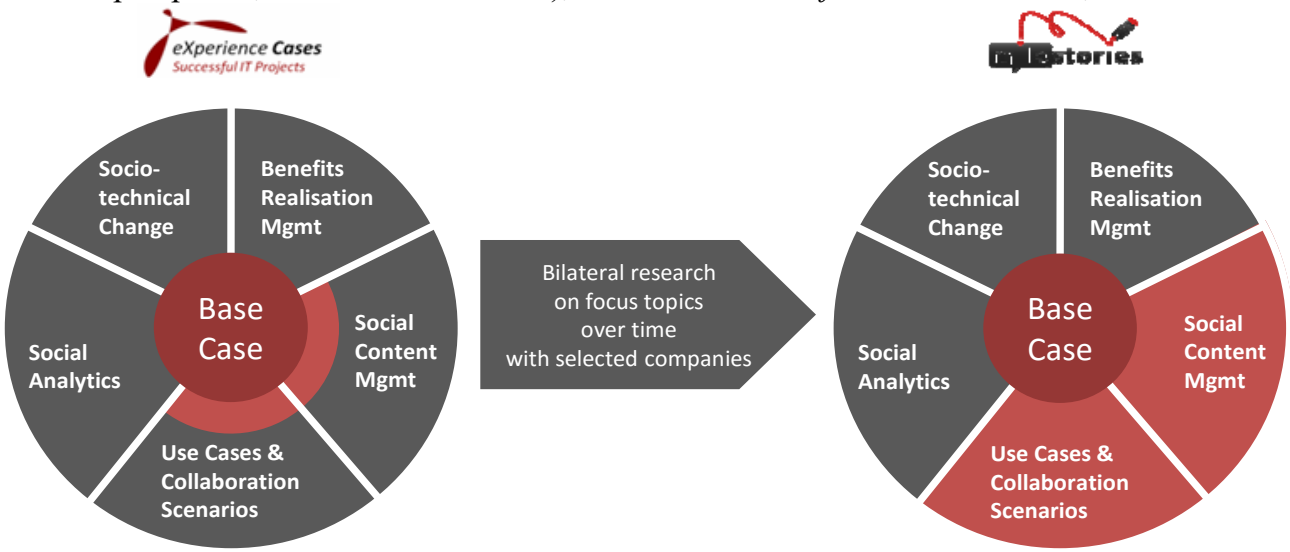

Figure 2: From eXperience base case to milestories 
mental methods are required for the analysis of the data and thus the generation of research findings from the cases. Over the years, authors have used eXperience cases in combination with grounded theory (coding approaches), cross-case analysis or have created in-depth narrative research cases from them. More than 100 research articles that use eXperience cases as data material have been published. Whilst eXperience cases capture in-depth information about the reasons and experiences from a technology introduction project (reasons, participants, processes and systems) they can normally only provide a reflective account at $a$ point in time. To address this the researchers involved in IndustryConnect use eXperience cases along with a complementary method - the "milestories" method.

Milestories. Milestories are complementary to eXperience cases and add the temporal perspective to a case by observing and "measuring" a situation at $m u l$ tiple points in time. We developed them for use in practice-based research to study projects of IS-enabled change and to capture the everyday activities and actions that occur as a project unfolds and progresses. Milestories are planned at regular intervals during a project to identify, examine and record the more qualitative aspects of the project such as: what has happened to date, why things did not happen as planned and the positive/negative unintended consequences that have occurred. They use concepts drawn from the Social Construction of Technology (SCOT), Social Shaping of Technology (SST) and Actor Network Theory (ANT) to identify actors, actions and activities and to understand socio-technical change as it occurs over time [41], [42].

As mentioned earlier, the eXperience base case and milestories are complementary to each other. For each of the organizations participating in IndustryConnect a base case is developed and deepened over time using milestories. The research process begins with the writing of the eXperience base case describing the implementation project from its start in the company to its current state. Researchers use a standardized interview guideline to collect the data in interviews with the responsible people for the project (individuals from business and IT departments). One researcher takes the lead for the base case, a second researcher accompanies the lead researcher to the interview and takes notes during the interview and shares in the writing of the case. This way the two researchers discuss and record what they have heard/observed (inter author agreement). The case is then shared with the interview partners for member checking for completeness and correctness [43]. The case document then goes through a review by a senior researcher as an additional means of quality control, that is to make sure all the relevant data has been captured and cross referenced and can be supported with evidence from interview transcripts/company supplied documents. In the next step, the base case is discussed in an internal workshop with the entire university research team. All core cases are shared among the team members and can be used as data source in their own research. During the interviews for the base cases the researchers identify topics of special interest for this particular company and for future research inquiry (these are shown as the outer layer of the base case Figure 2).

Examples for topics of special interest identified in the IndustryConnect Community are e.g. social adoption, social analytics, social business documents, use cases and collaboration scenarios. These topics reflect and guide the major part of the $\mathrm{PhD}$ theses of the involved junior researchers.

\subsection{Developing a Shared Understanding}

The collaborative work between the researchers and practitioners of IndustryConnect has led to many scholarly publications and the successful award of a competitive National Research Grant. The research outputs take various forms and makes use of different research designs. For example, a classification framework for use cases and collaboration scenarios and methods for the visualization of the scenarios was developed. This framework was subsequently used in a Design Science Research project to develop an eresearch database with use cases and scenarios from the company cases [44]. Other examples are the measuring of collaboration activities with analytical instruments from the research fields of social analytics and process mining. An important aim of the IndustryConnect participants is to find ways of better understanding collaboration activities in the digital workplace and these research articles provide both insight and guidance. Another topic of interest is the long-term management of social business documents; these are the artifacts being created within ECS. Such documents are conceptually and materially different to other document types [45]. Not only are they complex, compound documents, they also embody new characteristics that raise challenges for their management. In addition to a theorization of social business documents a research outcome in this area is recommendations and guidelines regarding their management, governance and compliance; a practical outcome welcomed by the industry partners who are struggling to manage this complexity. In addition to the tailored research methods described above the IndustryConnect community makes use of a reference framework for Enterprise Information Management, the $8 \mathrm{C}$ Model, that all participants have adopted and which also provides a 
shared vocabulary and common understanding for the joint research. The framework has been described in previous publications [46] and is an instrument for sense-making and used to organize and structure the discussion in the community. Figure 3 shows the current focus topics of IndustryConnect in the context of the $8 \mathrm{C}$ Framework.

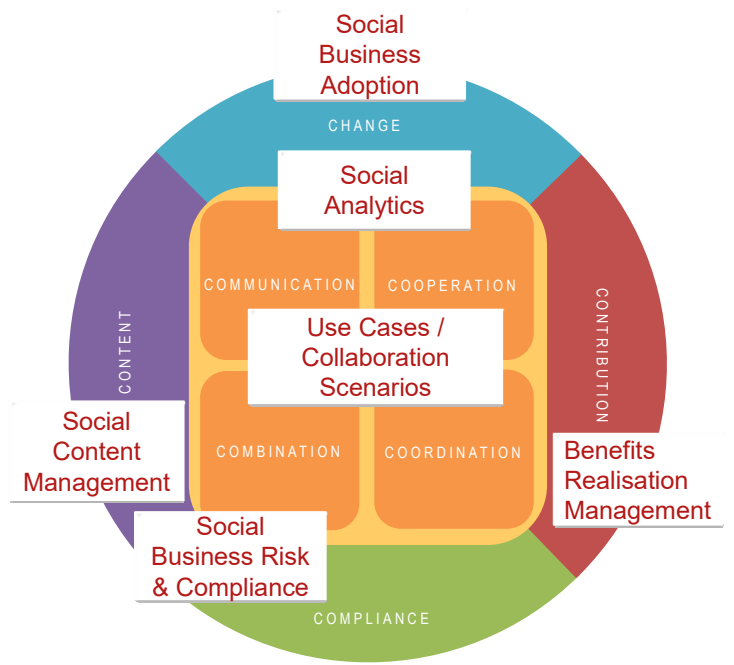

Figure 3: 8C Model as reference framework for focus topics

\section{Discussion and Lessons Learned}

Our goal with IndustryConnect was to develop a multi-organization practice-based research community where university researchers and practitioners work together to make sense of issues surrounding the design of the digital workplace and the use of ECS and to generate robust theorizations and actionable outcomes. It requires considerable effort to build and maintain such a community and meet the needs of the different constituencies. In the following we discuss some of the challenges encountered and lessons learned.

\subsection{Aligning interests \& community building}

The articulation work involved in building and sustaining a practice-based research community such as IndustryConnect is enormous [47] and from the start requires the building of respect and trust between the different constituencies. Initially some practitioners had doubts about the intentions of the group and the benefits they might gain from their participation. This response is not unusual from industry participants who have, in the past, worked with universities and have received no reciprocal benefits from the research. Making it clear that IndustryConnect is about generating actionable results as well as academic research was important from the outset. To achieve this we were able to draw on examples of our previous successful practice-based research and emphasize the process of co-design of research in the workshops and the defining of actionable outcomes.

We (as academics) had some reservations about how valuable our contribution might be for the very mature and experienced participants, especially those from large companies with expert staff specialized on the technologies in question. Several of the practitioners in the community have a $\mathrm{PhD}$ and all have in-depth experience of working with ECS. The participants value the opportunity to reflect in a systematic way on their work; in the flow of their daily work there is little time for reflection and theorizing and being part of the IC community provides this. Our most valued contribution has been to bring coherence to their work through translation research. That is, moderating, structuring and guiding the research cycles and analyzing, synthesizing and presenting the findings using scholarly research theories and frameworks in order to make sense of them. The interaction between participants in the meetings and the virtual community is very lively and space is made in every collaborative workshop for open discussion. The industry practitioners become specialized in scholarly theories and research methods (frameworks, models, cases, use cases etc.) and develop a deeper understanding of ECS and the digital workplace in their own companies and through the multi-organization nature of the community, they are able to compare, benchmark and learn from the experiences of other organizations. In a reflective interview one of the participants emphasized that "practitioners can really benefit from an engagement in this research community. I learn something new every time I attend the meetings".

\subsection{Theoretical \& practical outcomes}

One of the most important aspects of multiorganization practice-based research is to find a shared or common language. As we involved parties from outside the academic community, the way in which we described the constituent elements of the different theories in use (e.g. from CSCW and socio-technical change) and research approaches and methods needed to be sensitive to the variability of the vocabularies and experiences of different stakeholders. This raises questions about the design of research, the authority of professional knowledge and the ways we engage with 
practitioners to advance understanding and produce actionable knowledge [48]-[50].

IndustryConnect is organized around an action research cycle of planning, investigation, reflection, theorizing and action. The extent to which a research design can be specified in advance "is a matter of degree" [51]. The evolving, changing nature of ECS and the digital workplace means following the phenomenon wherever it takes us [13]. This calls for an open-ended approach to fieldwork and flexible and interactive research designs. Our inquiry methods and the analytical frameworks used to identify and comprehend the key actors, actions, and activities of ECS and digital work practice must be clear, robust and transparent to all research participants. To generate rigorous research findings significant emphasis must be placed on research ethics (informed consent) and on research quality and the capturing of reliable evidence (data quality and methodological rigor). In terms of research quality, two researchers attend all interviews, member checking is mandatory and findings are reviewed and open to scrutiny and discussion by the whole community.

There are many forms that university-industry research can take [52], [53]. With our multi-organization practice-based research community the approach is a genuinely collaborative, researching 'with' practitioners not researching 'on' them [54]. Community building is at the heart of our research program and implicit in every activity from the social activities, the virtual workplace and the collaborative workshops. Working out what works for everyone is an important part of the community building work, e.g. the frequency and length of the face-to-face workshops and sharing the organizational responsibilities for hosting them. These are part of the research design process and are seldom (if ever) discussed in research methods books or research training courses.

\subsection{Research training}

The narrowness of the skillsets of junior researchers, their focus only on tenure and publishing, on outcomes not processes have been raised as concerns about the limitations of research training in many $\mathrm{PhD}$ programs [2], [3], [7]. A significant aspect of the IndustryConnect practice-based research initiative is the conscious decision to weave research training and the mentoring of early career researchers into the research program. This means providing training and experience in all aspects of the research including: developing flexible and interactive practice-based research designs; conducting multi-participant data collection (e.g. focus groups, Delphi technique), interview design and management; research ethics and the conduct of prac- tice-based research; research information management and communicating results to both scholarly and practitioner communities. Through IndustryConnect we have provided our $\mathrm{PhD}$ students with an exceptional opportunity to work closely with industry partners in a collaborative research environment. However, this requires a special type of $\mathrm{PhD}$ student, one who is cooperative and open to sharing their findings with others in the team; this also requires them to trust in the quality of each other's work. They also have to be comfortable with the ongoing scrutiny of their work by a wider audience and prepared to put in the significant effort involved in organizing and managing the different community activities. The $\mathrm{PhD}$ students are involved in developing the base eXperience cases and milestories as well as their own topic areas. Each student is responsible for three or four companies, making sure the arrangements for site visits are cleared, keeping detailed logs of events and minutes of meetings and publishing interim results. There is a large administrative overhead in participating in practice-based research. We are fortunate that our $\mathrm{PhD}$ teams have attracted students who are open to this kind of research and who value the opportunity to work as part of a research community.

\section{Concluding remarks}

In this paper we have provided an account of the building and sustaining of a multi-organization practice-based research community. The strategies, methods and research instruments described in this paper have proven successful for us and we will continue to apply and refine them over the next years. As with all interactive research a high degree of openness must be maintained in order to accommodate new research directions. At the beginning we were uncertain about the best way to organize the initiative, how to finance it and how best to engage the practitioners and this was a process of 'working things out'. Questions regarding the physical meetings: how long, how frequently, how many individuals from one company should be allowed, were answered as we went along rather than being pre-planned.

Demonstrating the value of practice-based research and its outputs requires special attention. In contrast to the "rip and run" type of industry research where the researcher is simply harvesting data from companies, practice-based research requires significant mutual trust and relationship building; we are not researching with companies but with people in companies. The extent to which the participants feel part of the community is evidenced in their willingness to take turns in 
hosting the event at their company premises and to take a share of the administrative tasks attached to this, such as arranging the rooms and technology for the workshop, planning the social event and organizing accommodation etc.

Feedback from IndustryConnect participants has been entirely positive, providing us with examples and evidence of how the research findings have assisted them in understanding their own organizational contexts, managing socio-technical change and learning from the experiences of other companies. Now that participants are seeing and benefitting from the advantages, it is easy to attract new members. We may now have become victims of our own success, the question we are now addressing is "how big can such a community be and still be able to function effectively?

Industry-related research is highly valued by our university and a key focus of the President. Universityindustry research and its impact are evaluated and research groups are rewarded with additional funding, reputational value and promotion. However, such a model for practice-based research may not suit institutions with a dominant publish or perish culture, where quick wins are more important than building long term industry relationships. To build such relationships takes time and commitment, however the reward in terms of access to leading organizations and expert professionals has manifold payoffs. The possibility to gather timely and relevant research data and to work with companies over several years is leading us to richer longitudinal case studies, academic publications and expert-advisory opportunities.

\section{References}

[1] S. J. Winter and B. S. Butler, "Creating bigger problems: grand challenges as boundary objects and the legitimacy of the information systems field," J. Inf. Technol., vol. 26, pp. 99-108, 2011.

[2] R. M. Davison and M. G. Martinsons, "Methodological practice and policy for organisationally and socially relevant IS research: an inclusive-exclusive perspective," J. Inf. Technol., vol. 26, pp. 288-293, 2011.

[3] G. Walsham, "Are we making a better world with ICTs? Reflections on a future agenda for the IS field," J. Inf. Technol., vol. 27, pp. 87-93, 2012.

[4] N. J. Adler and H. Hansen, "Daring to Care: Scholarship that Supports the Courage of Our Convictions," J. Manag. Inq., vol. 21, no. 2, pp. 128139, 2012.

[5] M. Alvesson and J. Sandberg, Constructing research questions. Doing interesting research. London: SAGE Publications Ltd., 2013.
[6] B. Schneiderman, The new ABCs of research: achieving breakthrough collaborations. Oxford: Oxford University Press, 2016.

[7] R. D. Galliers, "In celebration of diversity in information systems research," J. Inf. Technol., vol. 26, pp. 299-301, 2011.

[8] D. Avison and J. Malaurent, "Is Theory King? Questioning the Theory Fetish in Information Systems," J. Inf. Technol., vol. 29, no. 4, pp. 327-336, 2014.

[9] D. A. Schön, "The Crisis of Professional Knowledge and the Pursuit of an Epistemology of Practice," in Competence in the Learning Society, J. Raven and J. Stephenson, Eds. New York: Peter Lang, 2001, pp. 185-207.

[10] N. J. Adler and A.-W. Harzing, "When Knowledge Wins: Transcending the Sense and Nonsense of Academic Rankings," Acad. Manag. Learn. Educ., vol. 8, no. 1, pp. 72-95, 2009.

[11] N. C. Ramiller and B. T. Pentland, "Management implications in information systems research: The untold story," J. Assoc. Inf. Syst., vol. 10, no. 6, pp. 474-494, 2009.

[12] B. Flyvbjerg, Making Social Science Matter: Why Social Inquiry Fails and How it Can Succeed Again. Cambridge: Cambridge University Press, 2001.

[13] C. A. Hardy and S. P. Williams, "Assembling EGovernment Research Designs: A Transdisciplinary View and Interactive Approach," Public Adm. Rev., vol. 71, no. 3, pp. 405-413, May 2011.

[14] A. H. Van De Ven and P. E. Johnson, "Knowledge for Theory and Practice," Acad. Manag. Rev., vol. 31, no. 4, pp. 802-821, 2006.

[15] A. M. Pettigrew, "Management Research after Modernism," Br. J. Manag., vol. 12, pp. 61-70, 2001.

[16] P. M. Leonardi, M. Huysman, and C. Steinfield, "Enterprise Social Media: Definition, History, and Prospects for the Study of Social Technologies in Organizations," J. Comput. Commun., vol. 19, no. 1, pp. 1-19, 2013.

[17] P. Schubert and S. P. Williams, "The Concept of Social Business: Oxymoron or Sign of a Changing Work Culture?," in 26th International Bled Conference, 2013, pp. 222-235.

[18] R. Williams and N. Pollock, "Moving Beyond the Single Site Implementation Study," Inf. Syst. Res., vol. 23, no. 1, pp. 1-22, 2012.

[19] D. Howcroft, S. Newell, and E. Wagner, "Editorial: Understanding the contextual influences on enterprise system design, implementation, use and evaluation," $J$. Strateg. Inf. Syst., vol. 13, no. 4, pp. 271-277, 2004.

[20] E. Monteiro, N. Pollock, O. Hanseth, and R. Williams, "From Artefacts to Infrastructures," Comput. Support. Coop. Work, vol. 22, no. 4-6, pp. 575-607, 2013.

[21] E. Monteiro and K. H. Rolland, "Trans-situated use of integrated information systems," Eur. J. Inf. Syst., vol. 21, no. 6, pp. 608-620, 2012.

[22] J. Greenbaum and M. Kyng, Design at work: cooperative design of computer systems. Hillsdale, NJ: L. Erlbaum Associates Inc., 1991. 
[23] H. Karasti, K. S. Baker, and F. Millerand, "Infrastructure Time: Long-term Matters in Collaborative Development," Comput. Support. Coop. Work, vol. 19, pp. 377-415, 2010.

[24] A. Elbanna and H. C. J. Linderoth, "The formation of technology mental models: the case of voluntary use of technology in organizational setting," Inf. Syst. Front., vol. 17, pp. 95-108, 2015.

[25] N. F. Doherty, C. R. Coombs, and J. Loan-Clarke, "A re-conceptualization of the interpretive flexibility of information technologies: redressing the balance between the social and the technical," Eur. J. Inf. Syst., vol. 15 , no. 6 , pp. 569-582, 2006.

[26] P. Raeth, N. Urbach, S. Smolnik, and B. Butler, "Corporate Adoption of Social Computing: A ProcessBased Analysis," J. Inf. Technol. Case Appl. Res., vol. 14 , no. 2, pp. 3-27, 2012

[27] T. J. Saldanha and M. S. Krishnan, "Organizational Adoption of Web 2.0 Technologies: An Empirical Analysis," in Americas Conference on Information Systems, 2010, pp. 1-10.

[28] J. Macnamara and A. Zerfass, "Social Media Communication in Organizations: The Challenges of Balancing Openness, Strategy, and Management," Int. J. Strateg. Commun., vol. 6, no. 4, pp. 287-308, 2012.

[29] S. P. Williams and C. Hardy, "Public eProcurement as socio-technical change," Strateg. Chang., vol. 14, pp. 273-281, 2005.

[30] P. M. Leonardi and S. R. Barley, "Materiality and change: Challenges to building better theory about technology and organizing," Inf. Organ., vol. 18, no. 3, pp. 159-176, 2008 .

[31] M. Aanestad and T. B. Jensen, "Collective mindfulness in post-implementation IS adaptation processes processes," Inf. Organ., vol. 26, pp. 13-27, 2016.

[32] K. Eason, "Afterword: The past, present and future of sociotechnical systems theory," Appl. Ergon., vol. 45, pp. 213-220, 2014.

[33] F. Kensing and J. Blomberg, "Participatory Design: Issues and Concerns," Comput. Support. Coop. Work, vol. 7, pp. 167-185, 1998.

[34] H. Oesterle, J. Becker, U. Frank, T. Hess, D. Karagiannis, H. Krcmar, P. Loos, P. Mertens, A. Oberweis, and E. J. Sinz, "Memorandum on designoriented information systems research," Eur. J. Inf. Syst., vol. 20, no. 1, pp. 1-4, 2011.

[35] R. Baskerville, K. Lyytinen, V. Sambamurthy, and D. Straub, "A response to the design-oriented information systems research memorandum," Eur. J. Inf. Syst., vol. 20, no. 1, pp. 11-15, 2011.

[36] J. Brown, "Reflexivity in the Research Process: Psychoanalytic Observations," Int. J. Soc. Res. Methodol., vol. 9, no. 3, pp. 181-197, 2006.

[37] B. B. Ragland, "Positioning the PractitionerResearcher: Five Ways of Looking at Practice," Action Res., vol. 4, no. 2, pp. 165-182, 2006.

[38] O. Fals Borda, "Participatory (Action) Research in Social Theory: Origins and Challenges.," in Handbook of Action Research Participative Inquiry and Practice, P. Reason and H. Bradbury, Eds. London: SAGE Publications Ltd., 2001, pp. 27-37.
[39] P. G. W. Keen, Shaping the Future: Business Design Through Information Technology. Cambridge, MA: Harvard Business School Press, 1991

[40] P. Schubert and R. Wölfle, "The eXperience Methodology for Writing IS Case Studies," in Americas Conference on Information Systems (AMCIS), 2007, no. 2, pp. 1-15.

[41] W. E. Bijker, P. H. Thomas, and T. J. Pinch, Eds., The Social Construction of Technological Systems: New Directions in the Sociology and History of Technology. Cambridge, MA: MIT Press, 1987.

[42] J. Law and J. Hassard, Eds., Actor Network Theory and After. Oxford, UK: Blackwell, 1999.

[43] J. A. Smith, "Evolving Issues for Qualitative Psychology," in Handbook of Qualitative Research Methods for Psychology and the Social Sciences, J. T. E. Richardson, Ed. Malden, MA: Blackwell, 2002, pp. 189-202.

[44] P. Schubert and J. H. Glitsch, "Use Cases and Collaboration Scenarios: How employees use sociallyenabled Enterprise Collaboration Systems (ECS)," Int. J. Inf. Syst. Proj. Manag., vol. 4, no. 2, pp. 41-62, 2016.

[45] V. Hausmann and S. P. Williams, "Issues for the longterm management of Social Business Documents," Int. J. Inf. Syst. Proj. Manag., vol. 4, no. 3, pp. 45-61, 2016.

[46] S. P. Williams, "Enterprise 2.0 and Collaborative Technologies," Working Report of the Research Group Business Software, May 2010, University of KoblenzLandau, Koblenz, Germany, 2010.

[47] H. Oesterle and B. Otto, "Consortium Research: A Method for Research-Practitioner Collaboration in Design-Oriented IS Research," Bus. Inf. Syst. Eng., no. 5, pp. 283-293, Aug. 2010.

[48] J. Orme, "Interactive Social Sciences: Patronage or Partnership?," Sci. Public Policy, vol. 27, no. 3, pp. 211-219, 2000

[49] A. Scott, J. Skea, J. Robinson, and E. Shove, "Designing 'Interactive' Environmental Research for Wider Social Relevance. Special Briefing no. 4." Economic and Social Research Council, 1999.

[50] A. van Buuren and J. Edelenbos, "Conflicting knowledge: why is joint knowledge production such a problem?," Sci. Public Policy, vol. 31, no. 4, pp. 289 299, 2004.

[51] M. Q. Patton, Qualitative Research and Evaluation Methods, 3rd ed. Thousand Oaks, CA: Sage Publications, 2002

[52] P. Schubert, N. Bjørn-Andersen, and T. Kilian, "Archetypes for Engaged Scholarship in IS," Int. J. Inf. Syst. Manag., vol. 1, no. 3, pp. 219-239, 2015.

[53] M. Mandviwalla, B. Fadem, M. Goul, J. F. George, and D. P. Hale, "Achieving Academic-Industry Collaboration with Departmental Advisory Boards.," MIS Q. Exec., vol. 14, no. 1, pp. 17-37, 2015.

[54] J. Heron and P. Reason, "The practice of co-operative inquiry. Research 'with' rather than 'on' people'," in Handbook of Action Research, P. Reason and $\mathrm{H}$. Bradbury, Eds. London: Sage, 2001, pp. 144-154. 